\title{
HIGH SENSITIVE C-REACTIVE PROTEIN IN ACUTE MI AND ITS CORRELATION WITH ONE YEAR MORTALITY
}

Chaithra S.P1, Harsha M.M²

HOW TO CITE THIS ARTICLE:

Chaithra S.P, Harsha M.M. "High sensitive C-reactive protein in acute MI and its correlation with one year mortality". Journal of Evolution of Medical and Dental Sciences 2013; Vol2, Issue 29, July 22; Page: 5293-5297.

ABSTRACT: INTRODUCTION AND OBJECTIVES: Cardiovascular diseases are the leading causes of mortality worldwide. The Acute Myocardial Infarction or Ischemic Heart Disease is rapidly increasing in India and in the developing countries. However, traditional risk factors alone do not explain this excess of Coronary Artery Disease. About 15-20\%of the coronary artery disease patients do not have traditional risk factors. Novel risk factors like hs-CRP may play a significant role in these patients. The correlation between hs-CRP and cardiovascular events is so strong that hs-CRP remains an independent risk factor for CAD. The aim of this study is to estimate hs-CRP levels in Acute Myocardial Infarction patients and to study their association with one year mortality. MATERIALS AND METHODS: 50 cases of Acute ST elevation MI admitted within 24 hours of onset of symptoms in ICCU in Basaveshwar Teaching and General Hospital, Gulbarga. 50 controls selected and matched with study subjects in all possible factors except the disease under study. Follow up done for upto one year. The novel risk factor hs-CRP was studied. RESULTS: This study was male dominated (72\%). Mean age of cases was 54.5years. Chest pain was the most common presenting symptom (90\%). High mean plasma hs-CRP $(0.615+0.419 \mathrm{mg} / \mathrm{dl})$ levels were noted among cases. Significant association was found between elevated hs-CRP levels and one year mortality. INTERPRETATION AND CONCLUSION: High plasma hs-CRP levels were noted among patients with Acute Myocardial Infarction and hs-CRP levels were found to be significantly elevated in the cases that expired. However larger studies are needed to substantiate these findings. KEY WORDS: Myocardial infarction, High sensitive $\mathrm{C}$ reactive protein, mortality.

INTRODUCTION: Despite recent advances in the management of diabetes and hypertension, cardiovascular disease remains one of the leading causes of death worldwide. ${ }^{1}$ Low and middle income countries, including the South Asian countries like India, contribute significantly to the global burden of cardiovascular disease. ${ }^{2}$ A substantial body of evidence has suggested that 4 modifiable risk factors -Smoking, Diabetes, Hypertension, and Dyslipidemia account for a significant portion of CAD. However these risk factors are not present in upto half of patients presenting with clinical manifestations of CVD. Hence there has been enormous interest in the identification of other measurable CVD risk factors. ${ }^{3}$

During the last few years a growing body of evidence has demonstrated that inflammation plays a pivotal role in the pathogenesis of atherosclerosis and its complications, and nowadays atherosclerosis is considered as an "inflammatory disease". Accumulating data demonstrate that elevated levels of circulating inflammatory markers predict an unfavourable cardiovascular outcome in asymptomatic subjects, patients with stable Ischaemic Heart Disease and in patients with Acute Coronary Syndromes. Improved knowledge of the molecular and cellular mechanisms of 


\section{ORIGINAL ARTICLE}

inflammation might not only further improve prognostic stratification but also allow us to identify novel therapeutic targets. 4 .

Several prospective studies have shown that hs-CRP has emerged as the golden marker of inflammation. It has been evaluated in many phases of coronary disease and has proven to be a reliable predictor of cardiovascular risk. It has a range of pro-inflammatory properties that potentially contribute to the pathogenesis, progress and complications of atheroma. Recent evidence lends support to the concept that CRP plays a direct role in promoting inflammation. ${ }^{5}$

OBJECTIVE: To estimate the levels of hs-CRP in Acute MI and its correlation with one year mortality.

MATERIALS AND METHODS: By using simple random sampling technique, 50 cases of MI admitted over a period of two years in Basaveshwar Teaching and General Hospital, Gulbarga were studied. A detailed history and thorough clinical examination was done as per the proforma and were investigated further. 50 controls were selected and matched with study subjects in all possible factors except the disease under study. Follow up was done upto one year.

INCLUSION CRITERIA: All the patients with Acute ST elevation MI of either sex who are admitted within 24 hours of onset of symptoms in ICCU in Basaveshwar Teaching and General Hospital.

EXCLUSION CRITERIA: Recent history of surgery or trauma within the preceding 2 months, renal insufficiency (serum creatinine>1.3), patients with CVA or previous history of CVA, malignancy, patients having evidence of infection, inflammatory disease, active hepatic disease, diabetes mellitus.

HS-CRP was estimated by immuno-nephelometry. The assay was carried out using DADE BEHRING BN ${ }^{\mathrm{TM}} 100$ system instrument.

RESULTS: The observations noted in the present study are as follows. Age in 50 cases of MI ranged from 22 to 70 years. The mean age in the study group is $54.5 \pm 12.28$. There were $36(72 \%)$ males and $14(28 \%)$ females in the study group. Male to female ratio is 2.6:1. Age in 50 controls ranged from 20 years to 75 years. The mean age in the control group was $54.3 \pm 11.52$. There were 50 controls of which $34(70 \%)$ were male and 16 (30\%) were female. 90\% of these cases presented with chest pain. hs-CRP (Mean \pm SD) in the study group was $0.615 \pm 0.419 \mathrm{mg} / \mathrm{dl}$ and in the control group was $0.15 \pm 0.081 \mathrm{mg} / \mathrm{dl}$. The circulating levels of hs-CRP were significantly higher in the study group than in the control group. Mortality of $14 \%$ was seen at the end of one year. Mean hs-CRP values in the expired cases were $1.4 \pm 0.36 \mathrm{mg} / \mathrm{dl}$ as compared to survivors $0.48 \pm 0.51$ with $\mathrm{t}=6.13$, $\mathrm{p}<0.001$, very highly significant. The mean hs-CRP levels in expired patients were found to be significantly higher as compared to the survivors. It is observed that of the deceased all the 7 (100\%) patients had increased hs-CRP. hs-CRP can thus be found to be an important predictor of cardiovascular mortality.

DISCUSSION: Coronary heart disease is a major cause of mortality and morbidity in the modern society. Mortality with acute MI is approximately $30 \%$ with more than half of the deaths occurring before the patient reaches the hospital. There is no one absolute CRP value precisely predicting risk of subsequent cardiac events for any given clinical presentation. However, from the data available, a 


\section{ORIGINAL ARTICLE}

value greater than $0.3 \mathrm{mg} / \mathrm{dl}$ either upon admission or at discharge appears to identify patients at increased risk for subsequent cardiac events. Evidence suggests that high-sensitivity CRP levels are one of the most powerful predictors of atherosclerosis and vascular death, offering prognostic value exceeding that of LDL cholesterol. The mechanistic basis of the predictive value of CRP may be its ability to incite endothelial dysfunction. Traditional assays for CRP do not have adequate sensitivity to detect levels required for vascular disease prediction. For this high sensitive Reactive protein assays have been developed and are now available worldwide.

In the present study, the hs-CRP values of cases and controls were Mean \pm sd $0.615 \pm 0.419 \mathrm{mg} / \mathrm{dl}$ and $0.154 \pm .081 \mathrm{mg} / \mathrm{dl}$ respectively, $\mathrm{p}<0.001$ being very highly significant. This was comparable to other studies like, Tenzin et al where the hs-CRP level in cases was $0.56 \mathrm{mg} / \mathrm{dl}$ and in controls was $0.22 \mathrm{mg} / \mathrm{dl}^{6}$

HS-CRP AND ONE YEAR MORTALITY: One year mortality in our study was found to be $14 \%$ and we also found that the HS-CRP levels were significantly higher in the deceased $(1.4 \pm 0.36 \mathrm{mg} / \mathrm{dl})$ as compared to the survivors $(0.48 \pm 0.51 \mathrm{mg} / \mathrm{dl}) \mathrm{p}<0.001$, very highly significant. In a study by Toss et al similar observations were made. The HS-CRP levels were significantly higher in the deceased $(1.5 \mathrm{mg} / \mathrm{dl})$ as compared to the survivors $(0.5 \mathrm{mg} / \mathrm{dl}) .^{7}$

Similarly, D. A. Marrow et al in their study concluded that CRP is a potent predictor of mortality independently and in combination with Troponin T in ACS. CRP levels were higher among patients who died than in survivors ${ }^{8}$. Large scale randomized multicentered studies are yet to be done to understand the proper association between hs-CRP and myocardial infarction.

CONCLUSION: hs-CRP levels were found to be elevated in patients with Acute MI and a significant association was noted between the concentrations of hs-CRP and one year mortality.

\section{BIBLIOGRAPHY:}

1. Teresa, Hoffman $\mathrm{K}$ and Mary Ann Tucker. Emerging risk factors and risk markers for cardiovascular disease: looking beyond NCEP ATP III Formulary; Aug 2009; 44: 237-247.

2. WHO Disease statistics. World health report 1999. Mortality by sex, cause and WHO regions, estimates for 1998.

3. Boss CJ and Lip GY. Elevated high-sensitive C-reactive protein, large arterial stiffness and atherosclerosis: a relationship between inflammation and hypertension. Journal of Human Hypertension. 2005; 19: 511-513.

4. Dominick J Angiolillo, Luigi M Biasuci, Giovanna Liuzzo, Filippo Crea, Inflammation in acute coronary syndromes; mechanism and clinical implications. Rev. EspCardiol, 2004; 57 (5): 433-46.

5. Pasceri V, Willerson JT, Yeh ET. Direct proinflammatory effect of C-reactive protein on human endothelial cells. Circulation 2000; 102:2165-2168.

6. Tenzin Nyandak, Arun Gogna, Sandeep Bansal, Manorama Deb. High Sensitive C - reactive protein (hs-CRP) and its Correlation with Angiographic Severity of Coronary Artery Disease (CAD). JIACM 2007; 8(3): 217-21. 
7. Toss H, Lindahl B, Siegbahn A, Wallentin L. Prognostic Influence of Increased Fibrinogen and C - reactive protein Levels in Unstable Coronary Artery Disease for the FRISC Study Group.Circulation, 1997; 96:4204-4210.

8. Morrow DA, Rifai N, Antman EM, et al. C-reactive protein is a potent predictor of mortality independently of and in combination with troponin $\mathrm{T}$ in acute coronary syndromes: a TIMI 11A substudy. Thrombolysis in Myocardial Infarction. J Am CollCardiol 1998; 31:1460-1465.

TABLE 1: Age and Sex distribution in the study group

\begin{tabular}{|c|c|c|c|c|c|c|}
\hline Age & Male & $\mathbf{\%}$ & Female & $\mathbf{\%}$ & Total & $\mathbf{\%}$ \\
\hline$\leq \mathbf{3 9}$ & 5 & 13.9 & 1 & 7.1 & 6 & 12 \\
\hline $\mathbf{4 0 - 4 9}$ & 8 & 22.2 & 1 & 7.1 & 9 & 18 \\
\hline $\mathbf{5 0 - 5 9}$ & 9 & 25 & 5 & 35.8 & 14 & 28 \\
\hline $\mathbf{2 6 0}$ & 14 & 38.9 & 7 & 50 & 21 & 42 \\
\hline Total & $\mathbf{3 6}$ & $\mathbf{1 0 0}$ & $\mathbf{1 4}$ & $\mathbf{1 0 0}$ & $\mathbf{5 0}$ & $\mathbf{1 0 0}$ \\
\hline
\end{tabular}

TABLE 2: Age and sex distribution in the control group

\begin{tabular}{|c|c|c|c|c|c|c|}
\hline Age & Male & $\mathbf{\%}$ & Female & $\mathbf{\%}$ & Total & \% \\
\hline$\leq 39$ & 5 & 14 & 1 & 6.3 & 6 & 12 \\
\hline $40-49$ & 7 & 20.6 & 2 & 12.5 & 9 & 18 \\
\hline $50-59$ & 9 & 26.5 & 6 & 37.5 & 15 & 30 \\
\hline$\geq 60$ & 13 & 38.2 & 7 & 43.7 & 20 & 40 \\
\hline Total & $\mathbf{3 4}$ & $\mathbf{1 0 0}$ & $\mathbf{1 6}$ & $\mathbf{1 0 0}$ & $\mathbf{5 0}$ & $\mathbf{1 0 0}$ \\
\hline
\end{tabular}

TABLE 3: Comparison of hs-CRP levels among study group and control group

\begin{tabular}{|c|c|c|c|c|}
\hline Number & Study group Mean \pm SD & Control group Mean \pm SD & t-test & p-value \\
\hline 50 & $0.615 \pm 0.419$ & $0.154 \pm 0.081$ & $\mathrm{t}=6.58$ & $\mathrm{P}<0.001$ VHS \\
\hline
\end{tabular}

Table 4: Mortality at the end of one year in patients with acute MI

\begin{tabular}{|c|c|c|}
\hline Mortality & Number of patients & Percentage \\
\hline Deceased & 7 & 14 \\
\hline Non deceased & 43 & 86 \\
\hline Total & $\mathbf{5 0}$ & $\mathbf{1 0 0}$ \\
\hline
\end{tabular}

Table 5: hs-CRP in relation to mortality

\begin{tabular}{|c|c|c|}
\hline Mortality & Number of cases & hs-CRP Mean \pm SD \\
\hline Deceased & 7 & $1.4 \pm 0.36$ \\
\hline t-test & & $t=6.13$ \\
\hline p-value & & $p<0.001$ VHS \\
\hline
\end{tabular}




\section{ORIGINAL ARTICLE}

\section{AUTHORS:}

1. Chaithra S.P.

2. Harsha M.M.

\section{PARTICULARS OF CONTRIBUTORS:}

1. Senior Resident, Department of General Medicine, KSHEMA, Manglore, Karnataka.

2. Senior Resident, Department of General Medicine, KIMS, Amalapuram, Andra Pradesh.

\section{NAME ADRRESS EMAIL ID OF THE} CORRESPONDING AUTHOR:

Dr. Chaithra B.P,

Senior Resident, Department of General Medicine, KSHEMA, Dirlakatti, Mangalore - 575018

Email: chaithrabpdoc@gmail.com

Date of Submission: 04/07/2013.

Date of Peer Review: 05/07/2013.

Date of Acceptance: 16/07/2013.

Date of Publishing: 17/07/2013 